sembled in this cosmopolitan congress today.

It has been our good fortune to witness in recent decades an unparalleled series of achievements in the fields of physical science. All of them, from anthropology and astronomy up to zoology, have yielded rich harvests of results; and one is prone to raise the question whether a like degree of progress may be expected to prevail during the century on which we have now entered. No man can tell what a day may bring forth; much less may one forecast the progress of a decade or a century. But, judging from the long experience of the past, there are few reasons to doubt and many reasons to expect that the future has still greater achievements available. It would appear that we have found the right methods of investigation. Philosophically considered, the remarkable advances of the past afford little cause for marvel. On the contrary, they are just such results as we should anticipate from persistent pursuit of scientific investigation. Conscious of the adequacy of his methods, therefore, the devotee to physical science has every inducement to continue his labors with unflagging zeal and confident optimism.

R. S. WOODWARD.

Columbia University.

\section{MICRO-ORGANISMS OF SOIL AND HUMAN WELFARE.*}

MAN has gained dominion in the earth not as a birthright, but by many struggles and by numerous conquests. Slowly during the ages he has gained accessions of knowledge and has succeeded in making more and more use of the forces of nature. The introduction of the art of printing enabled him to make readily and to keep permanently a record of his accomplishments; the discovery of the mariner's compass

* Presidential address read at the Buffalo meeting, August 24, 1904, of the American Microscopical Society. added immensely to his domain; the application of steam multipled a thousand times his power, and now the subjection of the electric forces makes him a veritable master over time and space. As a help in gaining knowledge applicable to the practical affairs of earth and life the microscope stands unrivaled. Its relations have been incomparably important in regard to the knowledge of man himself and to those things immediately connected with his daily existence and health. Bacteriology is a branch of microscopy or at all events could not have been developed without the aid of the microscope, and in this connection alone the instrument has been useful beyond any other piece of mechanism whatever in alleviating ills to which flesh is heir and in promoting and prolonging life.

So far bacteria have been more especially studied as disease germs. Witness the advance which has been made on account of those studies in medicine and surgery, in the efficiency of quarantines and in the prevention of epidemics. It is argued now in some quarters that even old age is a germ disease, and that immortality on earth is a possibility when bacteriology and its allied sciences come to perfection. I am to ask your attention at this time to some of the microorganisms of the soil and their relation to soil fertility. This is a technical subject. While it is not possible to treat it as a popular theme, it should not be difficult to show that there are matters here which, whether we are aware of it or not, intimately and immeasurably affect every human being on earth.

First a few words as to the organisms themselves. They are minute living creatures belonging to the vegetable kingdom, hence called plants, however unlike they are to the leafy structures usually alluded to by that name. Their most striking peculiarities are their exceedingly diminutive 
size, and their possibilities of reproduction. In the terms of the microscopist a hall micron is about the diameter of the smaller kinds and twice this for the larger ones. That is, from .0005 to $.001 \mathrm{~mm}$., or .00002 to .00004 inch. It requires 13 sheets of the typewriting paper on which this is written to measure in thickness one mm., therefore there is room across the cut edge of one sheet for about 77 of the larger or 144 of the smaller of these bacteria to lie side by side. Of course a single organism is absolutely invisible to the naked eye and can not be seen without more than 100 times magnification. To study bacteria effectively the best compound microscope is often taxed to its utmost limits.

Over and against the diminutive size may be placed the extraordinary powers of multiplication of these minute creatures. In the case of many common species any one of the organisms may become two by a simple process of self-division within thirty minutes of time, when conditions are favorable. At this rate at similar intervals of a half hour each, two become four, four become eight, eight become sixteen, etc. This continued for 48 half-hours, one day and night, makes the enormous number of $281,470,000,000$ individuals. This seems incredible, but a little calculation which can be made by any schoolboy will prove the statement. As shown by the census of 1900 , there were then in Illinois $4,881,450$ people. The number of bacteria produced in 24 hours from a single organism is, according to this, 58,327 times as many as the human population of Illinois, and is equal to something like 185 times the number of people in the whole world.

We are not to take from this that such a rate of multiplication ever actually continues for any very considerable time, for, small as these single organisms are, there would soon be room for nothing else on the earth. This rate of growth and self-division only occurs while all the conditions are favorable. Now, even if other things so continued, the prodigiously increasing numbers themselves would soon interfere with further advance. There are limitations here as there are to the number of people in a house. Even if nothing else prevents, their own excretions or other products may arrest growth. For instance, the souring of milk is for the most part caused by a particular species of bacteria. The individual organisms belonging to this species increase very rapidly in fresh milk at the proper temperature, and lactic acid is produced. But the proportion of this acid does not rise above eight tenths of one per cent., for this amount becomes prohibitive of further activity on the part of the organism. Its numbers do not further increase unless the acid is more or less neutralized by some alkaline substance. From some such cause our phenomenal numbers are not often found as the product of one bacterium in 24 hours, but the calculations do show approximate facts and do help us to explain observed results. One bacterium, perhaps one thirty-thousandth of an inch in diameter, far too small to be seen by the unaided eye, can do comparatively nothing while several thousands of them in a drop of broth may soon cause its putrefaction.

So much has been said of bacteria as germs of virulent diseases, as agents of pollution, as destroyers generally that we may well think of them as invisible enemies with which we must ever battle to live, or to have anything to live upon. To-day we are to discuss some of the benefits they confer upon us, and we shall see that not all good bacteria are dead bacteria. If they, or some of them, are destroyers and enemies to be feared, they, or some of them, 
are also helpers and colaborers to be favored.

The total number of bacteria in any soil capable of sustaining luxuriant vegetation is always very great and they vary in somewhat close proportion to the degree of fertility. In the first foot of rich garden earth about one to five millions per cubic centimeter commonly exist, though many times the larger number may be present when there is much decomposable matter and the conditions are favorable for rapid multiplication. The numbers rapidly decrease in the deeper layers, so that at three feet comparatively few are usually found, and at two or three times this depth they are practically absent. The numbers of all kinds have, however, less meaning than has the presence and activity of certain specific kinds-those which have to do with the original formation of soil and some active and efficient helpers in the maintenance of soil fertility.

ROCK REDUCERS. NITRIFIERS.

We all understand that what we term soil is not simply the crust of the earth in its original condition. The old-time rocks through long eons of time, by various agencies, have been crushed and comminuted, and the more or less pulverized materials have been mixed, transported and deposited by titanic forces and upon a scale of gigantic proportions. Mechanical agencies have been operative in the stupendous changes which have taken place in the reduction of the original rocks to the forms of sand and clays in strata as we find them, but only in recent times has it become known that certain microscopic living beings have had a share in the process. In spite of their diminutive size and of their low organization, in spite of their invisibility and of their individual nothingness, they are helpers in the accomplishment. It is custom- ary to speak of the crumbling of exposed surfaces of rocks as due to the weather, and the process is called weathering. But in these later days it has been found that this change is largely due to living organisms, just as the decay of fruits and the putrefaction of the flesh of animals, formerly supposed to be brought about by mere exposure to the air, are now well known bacterial operations. We know now that the process of canning fruits and meats succeeds not by keeping out the air as we formerly thought, but by keeping out bacteria. In the so-called weathering of rocks and the formation from them of soil, it is not so much the air, the rain, the frost, etc., which perform the work as it is our minute friends the bacteria.

Until recently it was supposed to be impossible that any bacteria could live without organic food supplies. It is and has been well known that green vegetation builds up organic matter from inorganic compounds under the energizing agency of sunshine. For instance, starch is formed in green leaves from carbon dioxide and water-the former absorbed from the air and the latter taken up by the roots; and there is no other way known to man by which starch is formed from elementary materials. A very large proportion of our food and that of all animals consists of starchy products so primarily produced, hence the operation is an immensely important one and all due to green leaves. They are almost miracle workers, but it had not been imagined that colorless bacteria could in any measure share with these higher forms of plant life as miracle-working agencies in this respect. Yet these bacteria that live on bare rocks get their sustenance from these and from the air, and in their life processes actually store up organic matter. That is, they are soil makers, fertility producers, advance agents 
in the making of a farm. They absorb and utilize the carbon dioxide of the air and when they die the carbonaceous compounds so formed are in part left as a component of what we call the humus element of soil. These bacteria are thus actively engaged in reducing the mineral substances to a pulverized form and as actively helping to provide a store of organic matter towards the formation of soil suitable for higher plants. It is remarkable, too, that these organisms are capable of accomplishing this work in the dark. As they do not derive their energy from light, as is the case with green plants, they must utilize some other radiant force or form of force for this purpose, possibly heat rays, or others not so well understood; or it is suggested that they derive their energy directly from the oxidizing processes they set up. At all events, they are wonder-working little creatures.

But our story concerning these particular kinds is not all told. Most microorganisms acting upon nitrogenous matters are destroyers of these compounds in such sense that the substances are rendered less available as food for higher plants. They are denitrifying agents. These peculiar species do just the reverse. They put nitrogenous compounds which are little or not at all utilized by higher vegetation in available shape and so contribute to soil fertility in another way. They can absorb ammoniacal gas washed by rains from the atmosphere or they can act upon insoluble salts of ammonia existing in the soil and form nitrites first, and then nitrates, in which latter condition common plants can use them. This is called nitrification, and the bacteria nitrifying agents. There are two groups of these workers. One set of species oxidize ammonia or its compounds to nitrites and another set further change these nitrites to nitrates.

A very curious thing is that these bacteria are not able to exert their activities in the presence of soluble organic matter-the very condition most favorable for most other micro-organisms. Even ammonia in a free state is an antiseptic to the nitrate formers. Soil that is liberally supplied with actively decomposing organic matter may have an abundance of these latter bacteria, but they are practically inactive until the decomposition has passed certain stages of its process. In the meantime this soil may be poorly suited for crops until later when the nitrifying processes are resumed. Denitrification can go on in a compact soil, but nitrification requires air. It seems that the stimulating effect of tillage is very considerably due to nitrifying activity, so induced; that is, we cultivate soil in part to favor these peculiar bacteriological friends. We see too how tile drainage may indirectly improve the productive capacity of the soil by securing better penetration of air and so again aid our friends, the nitrifiers. Again, these latter can not work in an acid medium. Sometimes the application of lime to certain soils proves to be greatly advantageous, not perhaps because there is too little of this substance for plant food, but because it corrects the acidity and permits, among other things, the nitrifying bacteria to work. Possibly in the full development of agricultural science there will be found more direct methods of securing the voluntary services, to their highest efficiency, of these minute friends of man.

It should be said that these nitrifying bacteria appear to be always present in all soils in sufficient numbers, hence there is little reason to suppose that anything can be gained by the addition of artificial cultures or of impregnated earth-processes which may be decidedly helpful in the case of certain other bacteria to be spoken of later-but it seems evident enough that 
methods of soil management have much to do in favoring or hindering the activities of these helpful little creatures. Some day farmers will come to understand that specialists working in laboratories and who for long hours gaze through the microscope are gradually gaining knowledge of fundamental importance to them.

\section{ROOT-TUBERCLE BACTERIA.}

As has been said, there are astonishing numbers of bacteria in all fertile soils, often attaining many millions in a little cube one centimeter (two fifth inch) in diameter, and numerous different kinds have been identified. Each of these kinds has certain special activities as well as peculiar structural characteristies. Most of them are concerned in the decomposition of organic matier and in this sense are destroyers, though we must not by any means call them enemies. If they do cause the fermentation or putrefaction of organic substances, these very operations are widely advantageous, since by this means useless materials are put out of the way or, perhaps, are converted into forms of utility. In this way the humus ingredient of fertile soils is mainly supplied.

But most of these innumerable organisms do not add anything to the soils, they simply change the state or condition of matters previously present. This is true of the nitrifying kinds mentioned above except that they do absorb the carbon dioxide of the air and contribute carbon to the soil in the solid form-a slim advantage, however, in the case of soils already formed, since green-leaved plants accomplish this on a much larger scale. The nitrifying bacteria are decidedly useful little creatures because of the desirable changes they bring to pass in organic materials present in the soil, not because of any contributions from an outside source through their agency.
There are, however, other peculiar bacteria not everywhere present among the hosts of living organisms commonly at home in fertile soils which do aid in such additions. If they are peculiar in distribution they are apparently more peculiar in their mode of action and in the results produced. After much careful investigation and no little difference of opinion it has been conclusively settled that green vegetation can not make direct use of the free nitrogen of the air, though combined nitrogen, mostly in the form of nitrates, is absolutely essential to their life and growth. These nitrates are freely soluble in water and tend to leach away. If, therefore, we should return to the soil everything that grows upon it, we should still find fertility decreasing, unless in some way nitrogen could be added from an extraneous source. The store of this substance is not inexhaustible in any soil. In spite of any contributions which could be made from the products of the soil itself, whether these were first fed to animals or not, this essential element of fertility would considerably and constantly diminish. A small amount of ammonia, the product of fermenting matters or of electric combinations, is washed from the air by rain, but too little seriously to affect the problem of the maintenance of soil fertility.

Now we know that soils in nature have not deteriorated. Without help from man they have, through thousands of years, gained instead of lost their nitrogenous supplies; though it must be true that great losses have in the meantime occurred by drainage. There must, therefore, be some means of supply, some accession from without which more than balances the losses. If green vegetation can not absorb and combine the free nitrogen of the air, of which the quantity is practically unlimited, something else must do so. 
During the twenty-five years from 1866 to 1891 observations and experiments by several investigators upon peculiar swellings on the roots, especially of leguminous or pod-bearing plants, resulted in showing that these are inhabited by bacteria, and that the green plants having them do in some way gain their needed nitrogen from the air when it is not available from the soil. This was a great discovery. It had long been known that these plants rendered soil more fertile for other crops afterward grown on the same land, and rotations had long been practised with clover as one of the crops for its fertilizing effects. How the clover acted as a fertilizer. was not known until about fifteen years ago. Since that time our knowledge upon the subject has very considerably increased and every year now something more is learned.

The facts seem to be in general somewhat as follows: leguminous plants unaided have no more ability to help themselves to the nitrogen of the air under any circumstances than have other green plants. Certain bacteria existing in the soil penetrate the soft tissues of young roots of legumes and multiply within these living tissues so as to form a little mass of gelatinous substance. Responding to the irritation produced, the plant builds a nodular structure about the bacterial invaders, not unlike the formation of a gall consequent upon the sting of an insect. Numerous nodules may be formed on the roots of one plant and they have characteristics peculiar to the species of plant on which they occur. Some are characteristically much larger than others, varying from the size of the smallest seeds to more than that of garden peas, or they grow in different shapes, or have different forms of grouping, etc. In some way not well understood these plants with nodules or tubercles are capable of getting sufficient nitrogen from the air abundantly to serve their purposes when the soil has no supplies, and when other plants must die from the want of it. Either the bacteria are direct agents in the process or they aid the plant itself to do what without such aid it can not do.

The number. of bacteria in one of these root tubercles is very large, altogether countless, yet the total number thus dwelling within the roots is insignificant when compared with the number in the soil outside. But these in the root are specifically different from those, and seem to have a decidedly different office to fulfil. As was said above, they are not common soil bacteria. They may, and sometimes do, live even some years in the soil outside of living roots, but they never become numerous among the other kinds and are often entirely wanting, however rich the soil may be otherwise.

There is a disputed question whether these root-dwelling bacteria all belong to one species with some temporary variation into races each adapted to a special kind of leguminous plant, or whether there are numerous species, almost as many as there are genera of legumes, upon which they are found. This may be thought to be an unprofitable inquiry, but it may mean more than we see at first glance. There is no longer any question but that there is some kind of difference among them. Those that form tubercles on the roots of clover fail entirely to develop on garden peas and on soy beans, and those that accompany soy beans appear to have no effect upon alfalfa. Some of them grow differently in artificial cultures and appear to have, under the microscope, various different characteristics. In certain instances it has been shown, however, that kinds usually associated with certain legumes can become adapted to others which they did not previously accompany, and this has been held 
to mean that in all cases the recognized form and functional differences are temporary modifications and that all are one natural species. There is really a very important matter here which we trust we shall soon know more about. If those which normally inhabit one species of leguminous plants can be modified by artificial cultures so as to grow upon another species of legumes, may further modifications be induced so that growth may take place upon some plant not a legume? There is no known reason why legumes particularly are hosts of these organisms to the exclusion of other kinds of vegetation. As a matter of fact, there are other and very different kinds of plants upon which similar root tubercles are found, namely, shrubs or trees of the genus Alnus or alder (not elder); two or three species of the family Eleagnacex, European shrubs sometimes cultivated with us for their silvery foliage; and-what appears more strange-upon coniferous trees of the southern hemisphere belonging to the genus Podocarpus. It has now become well known that the root tubercle organisms peculiar to alfalfa are not very widely distributed in our country and that in many cases the former can not be profitably raised without artificial inoculation of the soil. In such cases a remedy is found in scattering earth taken from a field where the plant has been successfully grown and where the nodules on the roots have been observed. A similar statement may be made with reference to soy beans, and there are areas, though not so common, where the bacteria which form tubercles on the roots of clover do not exist. In such areas the clover plant no more contributes to soil fertility than do other kinds of green vegetation.

We have asked: Can these legume organisms or some of them be made to form tubercles on other plants, for instance, upon maize? Here is a matter of the greatest moment. Undoubtedly they have some time in the past become adapted to leguminous vegetation. There is nothing to prevent the supposition that they may possibly be made to adjust themselves to corn. If so, what a triumph this would be for scientific experimentation. What an advance it would mark for scientific agriculture. We know that corn can be very decidedly modified in its chemical composition by processes of breeding. Types of grain can be produced in which, for instance, the nitrogenous percentage is greatly increased, and so a long way improved as food for man and beast. If, in addition to this, Indian corn can be made to furnish itself, through accommodating bacteria, with this higher nitrogen content directly from the exhaustless storehouse of the air, the agricultural miracle of the age will have been wrought. No one can predict whether or not this will ever come to pass. But from what is now known the endeavor to bring it to pass seems at least worth while.

Some years ago there were put up in certain German laboratories substances under the name of nitragin which were supposed to be pure cultures of living bacteria severally suitable for different leguminous crops, and it was thought that great results would follow the proper application of these cultures to fields seeded with the various legumes. Patents were taken out in Europe and in this country protecting the manufacture and use of these substances, but little seems to have come of the matter. Now the Department of Agriculture at Washington is sending out what are supposed to be improved cultures for a similar. purpose, and some very favorable reports of their use have been made. It is too soon to determine how valuable the results are 
to be. Surely tests are abundantly worth trying.

\section{NITROGEN FIXATION BY FREE BACTERIA.}

It was asserted above that little is known of the method by which leguminous plants in connection with root-tubercle bacteria accumulate nitrogen. It remains to be said that some experiments have shown that these same bacteria in artificial cultures can of themselves absorb and combine aërial nitrogen; that is, the legume bacteria are nitrogen fixers without any aid from leguminous plants. There is no proof, however, that this is done in nature, that these organisms, while in the soil outside of the root tissues, appropriate free nitrogen and build it into compounds which become suitable for plant food. It is, however, known that some other bacteria, not tubercle formers, do accomplish this task, for in unsterilized soils free from green vegetation an increase in the nitrogen content is found to take place under circumstances which preclude the accession except from the free nitrogen of the air; while in sterilized soils of the same kind under the same conditions no increase occurs. Since there is nothing else but bacteria in the unsterilized soil to which the phenomenon can be attributed, search has been carefully made for the active agents. After many tests upon numerous soil-inhabiting species, certain kinds of bacteria have been found which undoubtedly have the power of building the aërial nitrogen into combinations which subsequently serve as food for higher plants. In this case we must understand that the process is accomplished solely by the bacteria, and it is by different species from those forming root tubercles. In fact, several different kinds of bacteria and some molds are now known which thus contribute to soil fertility, but in most cases the quantity of nitrogen fixed is very small.
Two species, however, have been discovered which are apparently very efficient in the process, viz., Clostridium Pasteurianum Parzm. and Bacillus Ellenbachiensis Stutzer-Hartleb, and an artificially prepared substance called alinit has been placed on sale in Germany which appears to be a pure culture of the latter. Practical tests with alinit have not upon the whole shown that its application to soils results in any considerable increase in crops, though in some instances favorable reports have been made. The discovery that the organism has under. some conditions the effect of reducing nitrates to nitrites makes it seem less certain that the commercial preparation will prove valuable.

Here we pause. Our story has been a long one, yet only a meager account has been given of some of those soil bacteria which are efficient agents in preparing for, or furnishing, higher vegetation an essential constituent of their food. We have seen that in the most sterile soils certain nitrifying organisms are constantly at work utilizing ammonia washed from the atmosphere by rains or converting ammonia salts into nitrites, which are in turn oxidized by other species of bacteria into nitrates, the form suitable for the sustenance of higher vegetation. Again, the root-tubercle bacteria make a way for leguminous plants to use the free nitrogen of the air and to build up in their own structures compounds which contribute essentially to the fertility of the land when these structures decay. And then certain other soil bacteria are direct agents in the binding of free nitrogen into complex combinations within their own bodies, which upon their death are fitted by the agency of other bacteria to combine with the mineral constituents of the soil, to the effect that fertility is increased, even where the apparently bare earth seems lying idle, wasting in the sun. 
While these particular operations are in progress countless hoards of bacteria of various kinds are each exercising their natural functions in the rôle of destroyers or helpers, as the case may be. Surely we may think of the soil as a factory full of busy workers, causing incessant changes and modifications, rather than as a simple storehouse of accumulated riches.

The prosperity of peoples depends upon other factors than the fertility of the soil on which their homes are made, but those countries which are naturally most fertile furnish man more easily and more abundantly those things which may be used by him in increasing his power and in promoting his highest interests. In Illinois the local passenger traffic on the railroads is found to vary conspicuously with the difference over large areas in the quality of the soil, though all of the country is well populated. Not only is the number of the passengers in the regions of the best soils several times greater, but the difference in character of the men and women is also evident. The towns in the one case have great business houses, elegant residences, paved streets, electric railroads and lights, fine churches and school-houses, and a progressive, strong, hopeful and happy populace; while in the other these things are noticeably wanting, except in some measure the numbers of people. These take unconsciously a slower step, require more time in which to transact business and have less relish for physical or mental activity. They are evidently not so well fed and are in consequence really less capable of sustained exertion. Then, too, there is a stimulus in success itself which animates and inspires, while hopefulness is half the battle. Repeated failure of crops not only discourages the husbandman, but robs the entire community of life and push, and this is as true of mental and moral as of physical activities. Soil fertility and man's virility are closely related. Therefore, since certain bacteria have been proved to have direct and very important connection with the former, they have in like measure evident and decided bearing upon the latter. If all flesh is grass, all nutrition as applied to man seems to be ultimately conditioned upon the activity of certain micro-organisms of the soil.

Man has proved himself to be a mighty master. Formerly the storm-tossed oceans toyed like bubbles with his contrivances and the great billows were barriers to navigation. Now the tempestuous waters are luxuriant pathways of travel, and down in their. silent depths they pulsate from shore to shore with vibrant intelligence. Continents are spanned with iron and the massive locomotives thunder over the rivers and plunge under the mountains, defiant of opposition but delicately responsive to human control. How man has swept the forests from the face of the globe, and made at his will the wilderness to blossom as the rose! The earth, the air, the waters have yielded to him their. secrets and the forces thereof have become the obedient servants of his commands. But master as he is, potent as is his sway, he never could have gained a livelihood, nor could he now long maintain existence on the earth, without the aid of myriads of invisible, though organized and living, silent though industrious and efficient agents of the microscopic world. It becomes him, therefore, to seek acquaintance with these beneficent creatures and to find ways and means of favoring their life-giving activities.

T. J. BurRILL.

UNIVERSITY OF ILLINOIS.

\section{SCIENTIFIC BOOKS.}

The Classification of Flowering Plants. By Alfred Barton Rendle, M.A., D.Sc., F.L.S., assistant in the department of botany, Brit- 